\title{
Das stärkt den Rücken
}

\author{
YOGA bei Gesundheitsproblemen - Rückenmassagen sind wunderbar, aber zeitauf- \\ wändig und nicht ganz billig. Eine übung, die den ganzen Rücken massiert und leicht zu \\ machen ist, zeigen wir hier. Dazu sind nur eine gepolsterte Unterlage und ein wenig Schwung \\ nötig. Je häufiger die übung gemacht wird, umso mehr lässt sich der Schwung durch \\ bewusste Körperbewegung ersetzen. Ziel ist es, die Schaukelübung in Zeitlupe durchführen \\ zu können. Erforderlich sind aber ein gedehnter Rücken und starke Bauchmuskeln.
}

\section{Anhaltende Wirkung}

Ausgangsposition: Aufrecht auf die Unterlage setzen. Die Hände sind in den Kniekehlen, der Rücken ist ganz gestreckt (Abbildung 1). Wie schon bei vielen der gezeigten Übungen geht es darum, den Rücken immer wieder von unten nach oben auf- und abzurollen. Wer die Übung mit einem runden Rücken beginnt, massiert nicht den unteren Teil der Wirbelsäule und plumpst mit dem ganzen Gewicht auf die Brustwirbelsäule.

Bewegung: Mit einer Ausatmung den unteren Rücken runden und nach hinten rollen lassen (Abbildung 2). Wirbel für Wirbel runden und nach hinten rollen bis das Gewicht auf den Schulterblättern ruht und die Beine gestreckt sind (Abbildung 3). Mit der Einatmung über den gerundeten Rücken wieder zurück rollen in die Ausgangsposition und die Wirbelsäule erneut von unten nach oben strecken. Einige Male vor- und rückwärts rollen. Nachspüren: Wer mit der Übung den Tag beginnt, steht aus der Sitzposition auf und spürt der Wirkung in der Standhaltung nach. Obwohl die Übung Schwung gibt, kann sie auch vor dem Schlafengehen gemacht werden. Nach der Übung in eine bequeme Rückenlage kommen, Arme und Beine locker ablegen und mit geschlossenen Augen spüren, wie der Rücken auf der Unterlage aufliegt. Wer die Wirbelsäule vor dem Schlafen massiert, hat morgens weniger Probleme, wieder in Gang zu kommen.

\section{Schnelle Wirkung}

Wenn es nicht möglich ist, sich auf den Boden zu legen, dann kann das Abrollen der ganzen Wirbelsäule im Sitzen oder im Stand geübt werden.

Sitzposition: Aufrecht auf einem Stuhl sitzen und die Füße gut hüftgelenksweit voneinander entfernt fest auf dem Boden aufstellen, die Fußaußenkanten sind parallel. Die linke Hand auf dem linken Knie und die rechte Hand auf dem rechten Knie ablegen. Mit der Ausatmung den Rücken von unten nach oben Wirbel für
Wirbel abrollen, so dass der Oberkörper eine C-Form bildet und das Kinn in Richtung Brust sinkt. Mit der Einatmung den Rücken von unten nach oben Wirbel für Wirbel wieder aufrollen bis das Becken ganz aufgerichtet ist und die Wirbelsäule zwischen Steißbein und Kopfkrone gestreckt ist. Die Übung langsam und bewusst mehrere Male wiederholen.

Standposition: Zunächst etwas weiter als hüftgelenksweit die Füße mit den Außenkanten parallel aufstellen. Die Knie beugen und die linke Hand über dem linken Knie und die rechte Hand über dem rechten Knie aufsetzen. Die Daumen zeigen nach innen. Nun die Übung wie in der Sitzposition durchführen. Im Stand werden noch die Beinmuskeln gestärkt.

\footnotetext{
Prof. Dr. Ingrid Kollak

- Alice-Salomon Fachhochschule Berlin Yoga-Lehrerin BDY/EYU

_ Email:kollak@asfh-berlin.de (Betreff: Yoga bei ...)
}

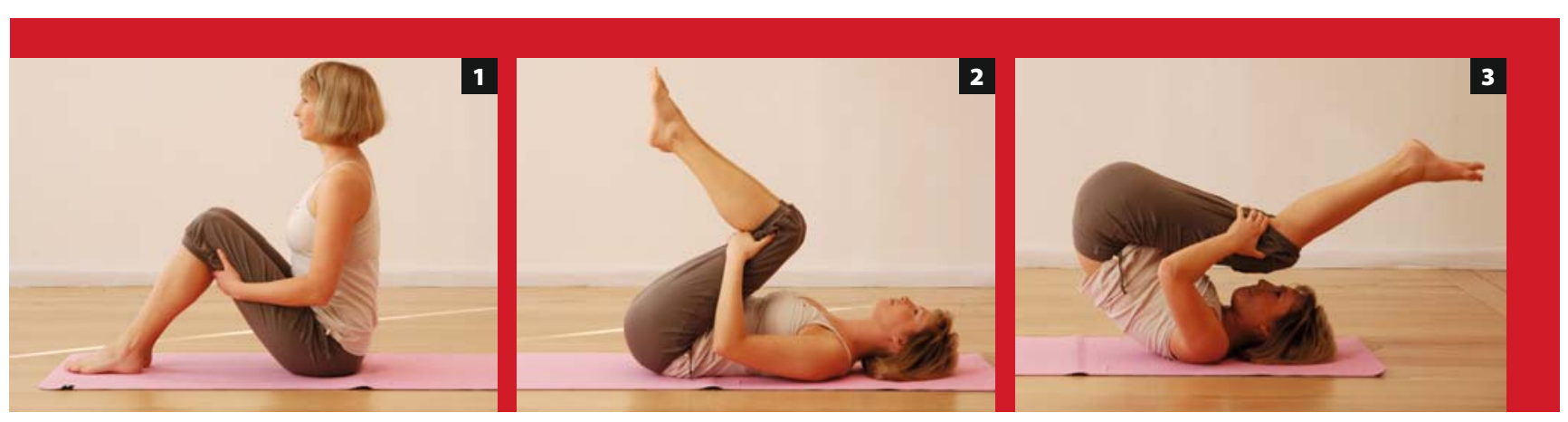

